\title{
A herança das “Luzes” para o século XXI
}

Diogo da Silva Roiz

D ENSAR qual a herança do pensamento produzido no século XVIII (cujos alicerces estavam em trazer as "Luzes" para o saber e para a humanidade) para o século XXI tem sido um questionamento muito comum entre vários "intelectuais" europeus e americanos. Que aquele período tenha sido extremamente produtivo e "vivaz" para o desenvolvimento de vários "campos do saber" (Badinter, 2007a, 2007b, 2009), que hoje o século XVIII nos é mais estranho e inóspito do que se imagina (Darnton, 2005), que seus desdobramentos não se limitaram apenas à Europa (Israel, 2009) e que suas raízes estão diretamente relacionadas com a formação das sociedades contemporâneas (Hunt, 2009), não há o que negar. O problema está mais em perceber o que ainda há de profícuo das "Luzes" para as sociedades do século XXI. Com o impacto dos questionamentos, produzidos desde o final do século XIX, sobre a "razão prática", a ideia de universalismo, progresso, desenvolvimento tecnológico, teleologia, razão e sentido dos processos históricos, mais parece que houve um esgotamento do "movimento da ilustração" (que com seu antropocentrismo questionou a religião e seus valores) do que caminhos ainda a serem seguidos. Contudo, ao efetuar oportunamente uma reavaliação criteriosa sobre o pensamento e os ideais das "Luzes", do século XVIII, Tzvetan Todorov indica que o "espírito das Luzes" ainda tem muito a nos dizer.

Ao longo de oito pequenos capítulos, o autor passa em revista o projeto, as re- jeições e desvios, os principais aspectos (como a autonomia, a laicidade, a verdade, a humanidade e a universalidade) do "espírito das Luzes", e compara o pensamento do século XVIII com as sociedades do século XXI - que acabaram sendo seu produto direto.

Para ele, não há como efetuar um retorno ao pensamento do século XVIII, tampouco isso seria oportuno para refletirmos os impactos das transformações produzidas nas últimas décadas do século passado, para as sociedades do século XXI. Mais oportuno, segundo ele, é efetuar uma avaliação do conjunto das propostas produzidas naquele período e elaborar uma análise comparativa entre o passado e o presente, e o presente e o passado, destacando como os problemas de cada momento foram pensados e resolvidos. Partindo desse princípio, o autor indaga que:

As grandes idéias das Luzes não têm origem no século XVIII; quando elas não vêm da Antiguidade, trazem os traços da Idade Média, do Renascimento e da época Clássica. As Luzes absorvem e articulam opiniões que, no passado, estavam em conflito [e esta é sua maior originalidade]. [...] As Luzes foram uma época mais de debate do que de consenso; de assustadora multiplicidade, aliás. (p.13-4)

Isso, porém, evidentemente, não descarta a existência de um projeto coerente e, em certo sentido, até articulado das Luzes. Para ele, três ideias estariam na base desse projeto. "O primeiro traço constitutivo do pensamento das Luzes consiste em privilegiar o que escolhemos 
e decidimos por nós mesmos em detrimentos daquilo que nos é imposto por uma autoridade externa" (p.14). Princípio declaradamente defendido por Kant, ao demonstrar que esse processo elevaria os homens a um estado de maioridade, como apresentou em seu artigo de 1784: “O que são as Luzes?”. Não é por acaso que, ao retornar a essa questão, Todorov indicará que a "primeira autonomia conquistada é a do conhecimento", que essa via de liberação do conhecimento promoverá o "desabrochar da ciência”, e que esse "princípio de autonomia revoluciona tanto a vida do indivíduo quanto a das sociedades" (p.17). Nesse aspecto, o conhecimento e a atenção que foram dados ao "outro" (ao oriental, ao americano e ao africano), por meio de romances e autobiografias, permitiram melhor compreensão da própria diversidade do gênero humano. Se:

O primeiro princípio é o da soberania, princípio já antigo que recebe aqui um novo conteúdo: a fonte de todo poder está no povo, e nada é superior à vontade geral. O segundo é o da liberdade do indivíduo em relação a todo poder estatal, legítimo ou ilegítimo, nos limites de uma esfera que lhe é própria; para assegurar essa liberdade, vela-se pelo pluralismo e pelo equilíbrio dos diferentes poderes. (p.19)

Nesse processo, sem dúvida alguma, todos "os setores da sociedade tendem a se tornar laicos, ainda que os indivíduos permaneçam crentes", porque as Luzes trouxeram consigo também a perspectiva de um Estado, que administrando todos os setores da sociedade lhe permitisse o oferecimento de uma justiça, de leis, de educação, de opinião pública e de imprensa periódica, sem tutelas religiosas. Mas o espírito das Luzes não se reduz unicamente à exigência de autonomia, mas traz também seus próprios meios de regulação. $O$ primeiro diz respeito à finalidade das ações humanas permitidas. Esta desce à terra: não visa mais a Deus, mas aos homens. Nesse sentido, o pensamento das Luzes é um humanismo ou, se preferirmos, um antropocentrismo. [...] A segunda restrição imposta à livre ação tanto dos indivíduos como das comunidades consiste em afirmar que todos os seres humanos possuem, por sua própria natureza humana, direitos inalienáveis. As Luzes absorvem aqui a herança do pensamento do direito natural, tal como formulada nos séculos XVII e XVIII: ao lado dos direitos que os cidadãos gozam no âmbito de sua sociedade, eles detêm outros, comuns a todos os habitantes do globo e, portanto, a cada um; direitos não escritos, mas nem por isso menos imperativos. (p.20-1)

Se, contudo, "todos os seres humanos possuem um conjunto de direitos idênticos, decorre que sejam iguais em direito: a demanda de igualdade decorre da universalidade" (p.21). A ideia de universalidade gerou, por sua vez, um interesse, cada vez maior, por sociedades diferentes. Mas

Os viajantes e os sábios não conseguem, do dia para a noite, deixar de julgar os povos longínquos a partir de critérios provindos de suas próprias culturas; no entanto, sua curiosidade é despertada, eles se tornam conscientes da multiplicidade de formas que a civilização pode assumir e começam a acumular informações e análises que, com o tempo, transformam-lhes a idéia de humanidade. Assim é para a pluralidade no tempo: o passado deixa de ser a encarnação de um ideal eterno ou um simples repertório de exemplos para se tornar uma sucessão 
de épocas históricas, cada uma com sua coerência e seus próprios valores. O conhecimento de sociedades diferentes daquela do observador lhe permite ao mesmo tempo considerar a si mesmo com um olhar menos ingênuo: ele não confunde mais sua tradição com a ordem natural do mundo. (p.22)

Essa consciência histórica e política do "outro" permite, por um lado, um maior distanciamento com as tradições e as ideologias, dando maior vazão à liberdade de expressão, e, por outro, a possibilidade de emancipação. No entanto, as consequências trágicas de muitos dos acontecimentos do século XX fizeram que nos distanciássemos de muitos desses ideais defendidos pelas Luzes.

O espírito das Luzes faz o elogio do conhecimento que liberta os seres humanos das tutelas exteriores opressoras. Mas ele não consiste em dizer que, estando tudo determinado e portanto passível de conhecimento, os humanos aprenderão a controlar integralmente o mundo e a moldálo segundo seus desejos. [...] Se quisermos hoje encontrar um apoio no pensamento das Luzes para enfrentar nossas dificuldades presentes, não podemos acolher todas as propostas formuladas no século XVIII - não somente porque o mundo mudou, mas também porque esse pensamento é múltiplo, não uno. É antes de tudo de uma refundação das Luzes que precisamos: preservar a herança do passado, mas submetendo-o a um exame crítico, confrontando-o lucidamente com suas conseqüências desejáveis e indesejáveis. Fazendo isso, não arriscamos trair as Luzes; ao contrário: a verdade é que as criticando, continuamos fiéis a elas, e colocamos em prática seu ensinamento. (p.27-9)

As Luzes, todavia, são veementemen-

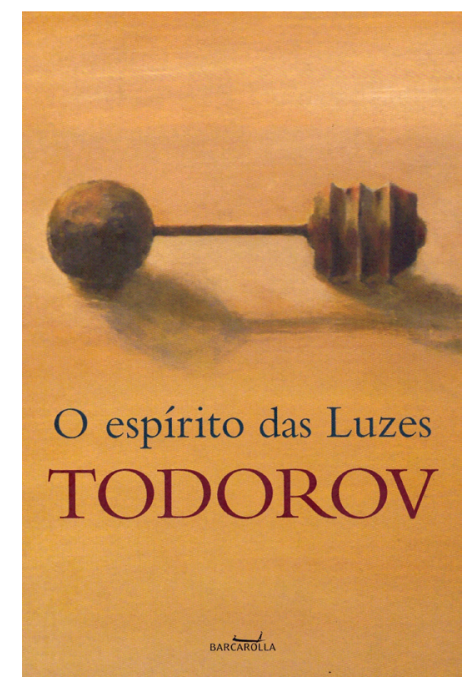

TODOROV, Tzvetan. O espirito das Luzes. Trad. Mônica Cristina Corrêa. São Paulo: Barcarolla, 2008. 158p.

te criticadas por, de certo modo, justificarem e permitirem o "colonialismo", viabilizarem os "totalitarismos" do século XX, conforme muitos autores indagaram. Contudo, essas rejeições e os inevitáveis desvios que o pensamento das Luzes também produziu antes voltam à questão de sua multiplicidade de propostas e ações, do que à unicidade completa de seus ideais. Nesse sentido, é importante rever cada um de seus pontos essenciais e reavaliar sua viabilidade para o século XXI, como é o caso de questões como: a autonomia, a laicidade, a verdade, a humanidade e a universalidade. Para Todorov:

A época das Luzes se caracteriza pela descoberta dos outros em seu estrangeirismo, tenham eles vivido outrora ou alhures: cessamos então de ver neles uma encarnação de nosso ideal ou um anúncio longínquo de nossa perfeição presente, como se fazia nas épocas precedentes. Mas esse reco- 
nhecimento da pluralidade no seio da espécie só permanece fértil se escapar ao relativismo radical e não nos faz renunciar à nossa humanidade comum. (p.130)

O espírito das Luzes traz também um outro problema, porque "encontram-se nele os ingredientes de épocas variadas, em todas as grandes civilizações do mundo; e, no entanto, ele só conseguiu se impor a partir de um momento preciso, no século XVIII, e particularmente num lugar, a Europa ocidental" (p.133). Justamente por essa razão, o autor irá se deter numa comparação entre o pensamento das Luzes e a Europa do século XXI. De acordo com ele:

Esses desenvolvimentos múltiplos dão testemunho, pois, da universalidade das idéias das Luzes, que não são, de forma alguma, apanágio apenas dos Europeus. Entretanto, é justamente na Europa que no século XVIII se acelera e se reforça esse movimento, é ali que se formula a grande síntese do pensamento que se difunde em seguida para todos os continentes: primeiro na América do Norte, em seguida na própria Europa, na América Latina, na Ásia e na África $[. .$.$] pode-se assinalar um traço$ presente na Europa e ausente noutros lugares: é a autonomia política, a do povo e do indivíduo. Esse indivíduo autônomo encontra aqui um lugar no próprio seio da sociedade, e não fora dela (como podia ser o caso dos "renunciantes" na Índia, dos místicos na terra do islã, dos monges na China). O próprio às Luzes européias é ter preparado o acontecimento conjunto dessas noções: indivíduo, democracia. (p.136-7)

Apesar disso, a Europa "não é a primeira a se beneficiar da pluralidade interior", porque essa "havia já sido res- ponsável pelo apogeu da cultura grega antiga”, que por sua “disposição geográfica [...] separadas por cadeias de montanhas garantia-lhe a independência; a língua e os interesses comuns favoreciam ao mesmo tempo a comunicação" (p.142). Ainda assim:

o que todas as nações européias possuem em comum - racionalidade científica, defesa do Estado de direito e dos direitos do homem - possui uma vocação universal, e não especificamente européia. Ao mesmo tempo, esse substrato comum não basta para organizar uma entidade política viável, ele deve ser completado por escolhas particulares, enraizadas na história e na cultura de cada nação. [...] a identidade da Europa e, portanto, sua "vontade geral", poderá se afirmar se nos apoiarmos nas análises feitas na época das Luzes; se, em vez de isolar tal qualidade para imputá-la a todos, tomássemos por base de unidade o estatuto acordado de nossas diferenças e as maneiras de delas tirar proveito: favorecendo a tolerância e a emulação, o livre exercício do espírito crítico, o distanciamento de si permitindo projetar-se em outrem e ter acesso assim a um nível de generalidade que inclui o ponto de vista de uns e outros. (p.146-7)

Para o autor, a capacidade de integrar um conjunto substancial de diferenças, distingue a Europa de outros grandes conjuntos políticos mundiais. Mas isso custou também muito caro: "antes de ser o continente que encarnava a tolerância e o reconhecimento mútuo, a Europa foi o das dilacerações dolorosas, dos conflitos chacinantes, das guerras incessantes" (p.148).

Apesar dessas importantes constatações, não há como negar que, mesmo na Europa, a questão da tolerância tem 
fronteiras muito tênues. Basta verificar as diferentes formas de tratamento dos europeus entre si, e deles para com os latino-americanos, africanos ou muçulmanos. E essas questões se tornaram ainda mais frágeis e latentes após os atentados terroristas aos Estados Unidos em 2001. Não há como negar a importância da herança das Luzes para melhor balizarmos as raízes das sociedades contemporâneas e equacionarmos medidas mais eficazes, até para pensarmos mais adequadamente o nosso momento histórico. Mesmo considerando os importantes trabalhos, que fizeram de Tzvetan Todorov um dos grandes "intelectuais" da atualidade, ao repensar as relações dos europeus com os americanos na época dos grandes descobrimentos dos séculos XIV e $\mathrm{XV}$, e suas análises das sociedades contemporâneas, não há como deixar de lado que o próprio projeto das Luzes, embora eficiente para pensarmos várias questões contemporâneas, foi fruto do século XVIII. Por isso, seus limites são inegáveis. Mas, evidentemente, não deixa de ser oportuna às reflexões que o autor empreendeu, até para pensarmos quais os limites e que herança resta das "Luzes" para o século XXI.

\section{Referências}

BADINTER, E. As paixões intelectuais: desejo de glória, 1735-1751. Trad. Clóvis Marques. Rio de Janeiro: Civilização Brasileira, 2007a. v.1.

As paixões intelectuais: exigência de dignidade, 1751-1762. Trad. Clóvis Marques. Rio de Janeiro: Civilização Brasileira, 2007b. v.2.

As paixões intelectuais: vontade de poder, 1762-1778. Trad. Clóvis Mar- ques. Rio de Janeiro: Civilização Brasileira, 2009. v.3.

DARNTON, R. Os dentes falsos de George Washington: um guia não convencional para o século XVIII. Trad. José Geraldo Couto. São Paulo: Cia. das Letras, 2005.

HUNT, L. A invenção dos direitos humanos: uma história. Trad. Rosaura Eichenberg. São Paulo: Cia. das Letras, 2009.

ISRAEL, J. I. Iluminismo radical. A filosofia e a construção da modernidade, 1650-1750. Trad. Claudio Blanc. São Paulo: Madras, 2009.

Diogo da Silva Roiz é doutorando em História pela UFPR, bolsista do CNPq. Professor do Departamento de História da Universidade Estadual de Mato Grosso do Sul (Uems), campus de Amambai. @ - diogosr@yahoo.com.br 